\title{
Effectiveness of dual and triple antiretroviral therapy in the treatment of HIV-infected children
}

\author{
Roberta M. C. Romanelli, ${ }^{1}$ Jorge A. Pinto, $^{2}$ Laura J. Melo, ${ }^{3}$ \\ Mariana A. Vasconcelos, ${ }^{4}$ Rafael de Matos Pereira ${ }^{5}$
}

\begin{abstract}
Objective: The use of antiretroviral therapy in HIV-infected children has been a widely discussed issue. The aim of this study was to compare the effectiveness of dual nucleoside analogue reverse transcriptase inhibitor (NRTI) regimens and three-drug regimens [2NRTI+ non-nucleoside reverse transcriptase inhibitor (NNRTI) or protease inhibitor (PI)] in a cohort of HIV-infected children.

Methods: The study was carried out in a referral center for the management of infected children, which is affiliated with the School of Medicine of Universidade Federal de Minas Gerais (UFMG). Those children whose antiretroviral therapy was implemented between January 1998 and December 2000 and who were followed until December 2001 were included in the study. Therapeutic failure or death was regarded as the endpoint in our analysis.

Results: A total of 101 patients were assessed, 58 (57.4\%) on dual therapy and 43 (42.6\%) on triple therapy. No statistically significant difference was observed between the groups in terms of gender, age, CD4+ count and baseline viral load. The average duration of dual therapy was 26.3 months (95\% CI $21.3-31.3$ ) and that of triple therapy was 34.3 months (95\%CI $29.2-39.5 \%$ ). There was therapeutic failure in $33(56.9 \%)$ patients on dual therapy and in $11(25.6 \%)$ patients on triple therapy $(\log r a n k=5.03 ; p=0.025)$. The relative risk of therapeutic failure of the dual therapy was 2.2 times higher (95\% CI 1.3-3.9). The percentage of initial CD4+ T cells was a predictor of risk for therapeutic failure $(p=0.001)$. Patients on triple therapy showed a more remarkable reduction in their viral load $(p=0.001)$.

Conclusion: Triple therapy was efficient for a longer time period and showed better virologic response than dual therapy in this cohort of HIV-infected children. Therefore, triple therapy should be the treatment of choice.
\end{abstract}

J Pediatr (Rio J). 2006;82(4):260-5: Acquired immunodeficiency syndrome, anti-HIV drugs, therapy.

\section{Introduction}

Antiretroviral (ARV) therapy has undergone remarkable changes since the HIV epidemics began. Since the approval of zidovudine (AZT) by the Food and Drug Administration (FDA), recommendations for the use of drugs in pediatric

1. Especialista em Pediatria, com Área de Atuação em Infectologia Pediátrica. Doutoranda em Pediatria, Faculdade de Medicina, Universidade Federal de Minas Gerais (UFMG), Belo Horizonte, MG, Brasil.

2. Professor adjunto, Doutor, Coordenador, Grupo de AIDS Materno-Infantil, Departamento de Pediatria, Faculdade de Medicina, UFMG, Belo Horizonte, MG, Brasil.

3. Residente de Pediatria, Hospital das Clínicas, UFMG, Belo Horizonte, MG, Brasil.

4. Residente de Pediatria, Hospital das Clínicas, UFMG, Belo Horizonte, MG, Brasil.

5. Residente, Clínica Médica, Fundação Hospitalar do Estado de Minas Gerais (FHEMIG), Belo Horizonte, MG, Brasil.

Manuscript received Nov 23 2005, accepted for publication Apr 262006 .

Suggested citation: Romanelli RM, Pinto JA, Melo LJ, Vasconcelos MA, Pereira RM. Effectiveness of dual and triple antiretroviral therapy in the treatment of HIV-infected children. J Pediatr (Rio J). 2006;82:260-5. patients are always made after recommendations for adult patients have been established, due to ethical issues, and to the difficulty in defining the appropriate doses and in conducting clinical trials in this age group. ${ }^{1}$

Despite the clinical benefits initially provided by AZT, monotherapy was efficient for a short time period, and then the combination of drugs was necessary in order to achieve a more efficient therapeutic response. In the early 1990s, new nucleoside reverse transcriptase inhibitors (NRTIs) were released into the market, and dual therapy, which consisted of the combination of two NRTIs, was recommended for a better therapeutic response. ${ }^{2-4}$

In 1995, protease inhibitors (PI) gave a new outlook on the treatment of AIDS, as their use allowed for a longlasting therapeutic response, with larger regeneration of $\mathrm{CD} 4+\mathrm{T}$ cells and larger reduction of the viral load, but their use in children was allowed only in 1997.2,5,6 After that, non-nucleoside reverse transcriptase inhibitors 
(NNRTIs) expanded the therapeutic arsenal, and their use in children was allowed after $1998 .^{2}$ Thus, the advent of these new antiretroviral drugs gave rise to triple therapy, which consisted of two NRTIs and one $\mathrm{PI}^{6-8}$ or two NRTIs and one NNRTI. ${ }^{9}$ Inhibition of viral replication became the ultimate goal, and early and aggressive therapy was used as the basis of ARV therapy. ${ }^{10-12}$

Combined therapy improved the prognosis of AIDS by increasing the life expectancy of adults and children. ${ }^{13-15}$ However, after careful consideration, the guidelines for ARV therapy had to be changed at the beginning of the third decade of the HIV/AIDS pandemics. The combination of available ARV drugs for highly active antiretroviral therapy (HAART) could not eradicate the HIV, and the suppression of viral replication was not always achieved.16,17 Even adults submitted to HAART with a good immune and virologic response showed suppression of viral replication for no longer than 2 years. ${ }^{18}$ Moreover, treatment compliance, side effects and drug toxicity, such as lipodystrophy and hyperglycemia, interfere with the quality of life, especially in asymptomatic patients. ${ }^{19}$

Some questions arose as to the benefits of initiating ARV therapy in asymptomatic patients or postponing it. So far, the benefits of early therapy have not outweighed the risks of long-lasting treatment. For this reason, current recommendations suggest postponing treatment even in adults. ${ }^{20-22}$

Another pending question is related to the selection of the best therapy. The 2004 Brazilian Guidelines for Antiretroviral Therapy in HIV-Infected Children ${ }^{23}$ still recommends the use of dual therapy for patients with mild or moderate symptoms of AIDS.

The aim of the present study was to assess the effectiveness of ARV therapy in children treated at a referral center for HIV/AIDS patients in Belo Horizonte, state of Minas Gerais, Brazil, and to evaluate the response and duration of dual and triple therapy. Both CD4+ cell count and viral load were considered at the beginning of treatment as predictive factors of the duration of first treatment and of the immune and virologic response after 8 to 12 weeks of ARV therapy.

\section{Methods}

This was a retrospective, observational cohort study carried out at the Training and Referral Center for Infectious and Parasitic Diseases (Centro de Treinamento e Referência em Doenças Infecto-Parasitárias, CTR/ DIP) of the School of Medicine of Universidade Federal de Minas Gerais (UFMG). The patients were diagnosed with HIV infection according to standard methods and were submitted to clinical, immunological and viral assessments at three-month intervals. ${ }^{23,24}$
The CD4+ count ( $T$ helper cells) was performed by flow cytometry, using Coulter EPICS-XL ${ }^{\circledR}$ or Becton Dickson Facs Count ${ }^{\circledR}$. The serum viral load was determined by nucleic acid sequence-based amplification (NASBA Organon-Teknica ${ }^{\circledR}$ ).

The inclusion criteria were the following: a) patients younger than 13 years with the diagnosis of HIV/AIDS submitted to their first ARV therapy; b) ARV therapy between January 1998 and December 2000. Patients who missed their follow-up appointments for a period longer than 6 months were regarded as lost to follow-up and were not included in the analysis.

The patients were assigned to either of the following groups: a) dual therapy (two NRTIs) and b) triple therapy (two NRTIs + one PI or one NNRTI). The patients were classified as having mild/moderate or advanced disease according to the Centers for Disease Control and Prevention (CDC) criteria: 25 those in categories $N 1, N 2, A 1, A 2, B 1$, and $B 2$ showed mild/moderate disease, and those in categories N3, A3, B3, C1, C2, and C3, advanced disease.

Even though the Brazilian Guidelines for Antiretroviral Therapy in HIV-Infected Children ${ }^{23}$ recommends dual therapy in children with mild to moderate disease, other groups have recommended triple therapy or HAART. 24,26 In the study population, it was the attending physician who decided between dual and triple therapy, without interference from the researchers.

The criteria for therapeutic response, therapeutic failure, and intolerance were in accordance with the definitions established by the Brazilian Guidelines for Antiretroviral Therapy in HIV-Infected Children 23 and by the US Guidelines for the Use of Antiretroviral Agents in Pediatric HIV Infection. 24

The characteristics of the groups at the beginning of treatment were assessed using the chi-square test $\left(\chi^{2}\right)$ and Student's $t$ test. The proportion of failures between the groups was calculated by the survival curve using the Kaplan-Meyer method and the log rank test. The relative risk (RR) for therapeutic failure was calculated using a $95 \% \mathrm{CI}$. Baseline age, CD4+ count and viral load were assessed as predictive factors for the discontinuation of the first therapeutic regimen through the $t$ test.

The data were analyzed using the SPSS for Windows version 8.0. A p value of less than 0.05 was regarded as statistically significant.

The data were regarded as private information, and an informed consent form was signed by parents or legal surrogates. The study was approved by the Research Ethics Committee of UFMG.

\section{Results}

One hundred fifteen children met the inclusion criteria. Four of them were considered lost to follow-up and did not 
remarkably differ from the analyzed group in terms of gender, age, therapeutic regimen, classification, CD4+ count and viral load.

Sixty-five patients were submitted to dual therapy ( $86.1 \%$ on AZT +ddI) and 46 to triple therapy ( $71.7 \%$ on $A Z T+d d I+N F V)$. Other therapeutic regimens were: $A Z T+3 T C ; d 4 T+d d I ; A Z T+3 T C+N F V ; d 4 T+d d I+N F V$; $A Z T+d d I+E F F ; A Z T+d d I+R T V ;$ and $A Z T+3 T C+R T V$. Initial therapy was modified in 10 patients due to intolerance or toxicity. These patients were excluded from the study.

Therefore, the efficacy of the first ARV therapy was assessed in 101 patients, 58 of them on dual therapy and 43 on triple therapy. Age, classification, gender, CD4+ T cell count and viral load at the beginning of therapy were similar in both groups (Table 1).

Four patients on initial dual therapy died. Therapeutic failure was observed in 33 (56.9\%) patients on dual therapy and in 11 (25.6\%) patients on triple therapy. Patients on dual therapy had an RR of 2.2 (95\% CI 1.33.9) of therapeutic failure. Therapeutic failure occurred due to virologic failure in $19(43.2 \%)$, clinical and virologic failure in five $(11.4 \%)$, immunologic and virologic failure in three $(6.8 \%)$, clinical, immunologic, and virologic failure in one $(2.3 \%)$, clinical failure in four $(9.1 \%)$, immunologic failure in two $(4.5 \%)$, clinical and immunologic failure in two $(4.5 \%)$, death in two $(4.5 \%)$, and undefined cause in six $(13.7 \%)$.
The average duration of initial dual therapy was 26.3 months (95\%CI 29.2-39.5) and, and of triple therapy, 34.3 months (95\%CI 29.2-39.5), with a log rank $=5.03$ and $p=0.025$. The mean difference in the duration of therapy was 8 months (Figure 1 ).

There was no statistically significant difference between the treatment groups among patients classified as having mild/moderate disease $(\log$ rank $=0.14$ and $p=0.71$ ). However, patients with advanced disease showed a more pronounced difference in duration of treatment regimens $(\log$ rank $=16.33$ and $p<0.001)$

Given the fact that the groups were comparable at the beginning of treatment (Table 1 ), only the percentage of CD4+ $T$ cells showed statistical difference in the groups in which the first ARV therapy was successful or failed (Table 2).

The comparison of immunologic and virologic response between dual and triple therapy after 8 to 12 weeks of ARV administration revealed a larger reduction of the viral load in patients submitted to triple therapy (Table 3 ).

\section{Discussion}

The results obtained here demonstrate that HIVinfected children responded better to the triple ARV therapy, which showed a more remarkable reduction of the viral load $(p=0.001)$, longer duration $(p=0.025)$ and

Table 1 - Demographic, immunologic and virologic characteristics of treatment groups at the beginning of the first ARV therapy, CTR-DIP, 1998 through 2001

\begin{tabular}{|c|c|c|c|}
\hline Variable & $\begin{array}{c}\text { Dual } \\
(n=58)\end{array}$ & $\begin{array}{c}\text { Triple } \\
(n=43)\end{array}$ & $\mathbf{p}$ \\
\hline Male gender (\%) & $32(55.2)$ & $20(46.5)$ & 0.39 \\
\hline \multicolumn{4}{|l|}{ Classification } \\
\hline $\mathrm{A} 2$ & $13(22.4 \%)$ & $6(14 \%)$ & 0.17 \\
\hline A3 & $3(5.2 \%)$ & $3(7 \%)$ & \\
\hline B1 & $9(15.5 \%)$ & 0 & \\
\hline B2 & $15(25.9 \%)$ & $6(14 \%)$ & \\
\hline B3 & $6(10.3 \%)$ & $8(18.6 \%)$ & \\
\hline $\mathrm{C} 1$ & $1(1.7 \%)$ & $4(9.3 \%)$ & \\
\hline $\mathrm{C} 2$ & $2(3.4 \%)$ & $3(7.0 \%)$ & \\
\hline $\mathrm{C} 3$ & $9(15.5 \%)$ & $13(30.2 \%)$ & \\
\hline Age in months, mean (SD) & $36.9(33)$ & $29.1(32.5)$ & 0.25 \\
\hline $\mathrm{CD} 4+$ percentage, mean $(\mathrm{SD})$ & $17(7.6)$ & $20.1(9.3)$ & 0.09 \\
\hline absolute CD4+, $<1$ year, mean $(S D)(n=13 ; 19)$ & $905(447)$ & $799(431)$ & 0.54 \\
\hline absolute $C D 4+, 1$ to 5 years, mean $(S D)(n=34 ; 19)$ & $883(802)$ & $697(643)$ & 0.42 \\
\hline absolute CD4+, $>5$ years, mean $(S D)(n=11 ; 5)$ & $530(393)$ & $340(356)$ & 0.39 \\
\hline \multirow[t]{2}{*}{ Viral load, copies/mL, mean (SD) } & 1.236 .555 & 1.603 .021 & 0.63 \\
\hline & $(3.927 .217)$ & $(2.954 .197)$ & \\
\hline Viral load, logarithm, mean (SD) & $5.3(0.8)$ & $5.6(0.8)$ & 0.09 \\
\hline
\end{tabular}

ARV = antiretroviral; CTR/DIP = Training and Referral Center for Infectious and Parasitic Diseases; SD = standard deviation. 
a smaller percentage of therapeutic failure $(R R=2.2$ for dual therapy). The inclusion period was established in order to avoid a selection bias, given the history of available ARV therapy, and to avoid differences related to the longer duration of dual therapy.

Even though the virologic response after 8 to 12 weeks of ARV therapy showed a more remarkable reduction of the viral load in patients submitted to triple therapy ( $p=0.001)$, no statistically significant difference was found in the immune response. Nevertheless, the low CD4+ count at the beginning of treatment proved to be the best predictor of therapeutic failure $(p=0.001)$. This is an important piece of information, considering that it is best to start therapy before the immune system is severely compromised. 27,28

Treatment adherence is crucial for a good therapeutic response, and any difficulty in understanding, administering and storing the drugs is a hindrance in these cases. Given the adverse effects of ARV therapy and the therapeutic regimens that require the use of large amounts of drugs, adherence to triple therapy is supposedly worse than with dual therapy. However, even with this supposedly worse compliance, the analysis of the survival curve for the first dual and triple treatments showed that the latter was more beneficial (Figure 1).

International studies have shown advantages of triple therapy in the pediatric population. The PENTA $5^{6}$ trial revealed that protease inhibitors were more efficacious in children that had not been treated before. Although the present study is not a randomized one, the group of patients receiving triple therapy showed similar virologic benefits, with an average reduction of $2.5 \mathrm{log}$ in serum viral load after 8 to 12 weeks of therapy (Table 3 ).

Nachman et al. ${ }^{7}$ (PACTG 338) published the results of a clinical trial with patients that had already been

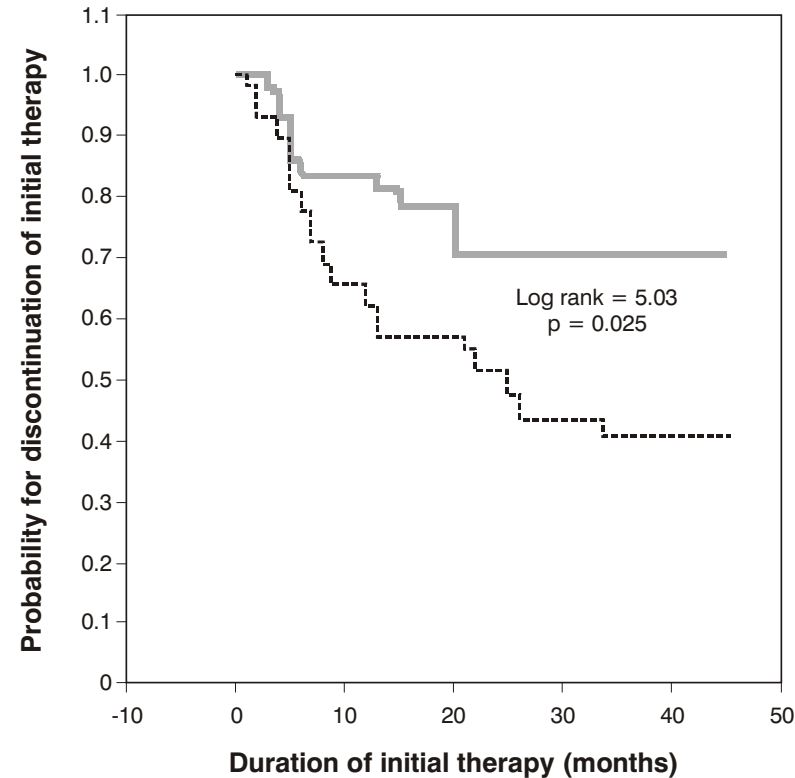

Treatment groups: 2 NRTI + 1 PI/NNRT -.---.- 2 NRTI

Figure 1 - Survival curve for dual and triple therapy in children submitted to their first ARV therapy, CTR-DIP, January 1998 through December 2001

ARV = antiretroviral; CTR/DIP = Training and Referral Center for Infectious and Parasitic Diseases; NRTI = nucleoside reverse transcriptase inhibitors; NNRTI = non-nucleoside reverse transcriptase inhibitors; $\mathrm{PI}=$ protease inhibitors

using NRTIs, which may have hindered the virologic response. Triple therapy ( $A Z T+3 T C+R T V$ ) had a larger number of patients with an undetectable viral load for a longer time period. To avoid interference from any previous study, the present study assessed only patients submitted to their initial ARV regimen.

Table 2 - Baseline age, CD4+ Tlymphocytes, and viral load as predictors of initial ARV treatment discontinuation, CTR-DIP, 1998 through 2001

\begin{tabular}{|c|c|c|c|}
\hline \multirow[t]{2}{*}{ Variable } & \multicolumn{2}{|c|}{ Groups } & \multirow[t]{2}{*}{$\mathbf{p}$} \\
\hline & $\begin{array}{l}\text { Treatment failure } \\
\qquad(n=44) \\
\text { Mean (SD) }\end{array}$ & $\begin{array}{l}\text { Treatment success } \\
\text { (n= 57) } \\
\text { Mean (SD) }\end{array}$ & \\
\hline Age in months & $37(33.3)$ & $30.9(32.5)$ & 0.35 \\
\hline CD4+ percentage & $15.1(6.6)$ & $21(9.0)$ & 0.001 \\
\hline Absolute $\mathrm{CD} 4+,<1$ year $(\mathrm{n}=12 ; 20)$ & $750(440)$ & $899(431)$ & 0.38 \\
\hline Absolute $C D 4+, 1$ to 5 years $(n=23 ; 30)$ & $655(512)$ & $943(879)$ & 0.19 \\
\hline Absolute $C D 4+,>5$ years $(n=9 ; 7)$ & $395(250)$ & $553(517)$ & 0.46 \\
\hline Viral load, copies/mL & $1.054 .007(2.195 .836)$ & $1.634 .886(4.194 .522)$ & 0.46 \\
\hline Viral load, logarithm & $5.2(0.8)$ & $5.5(0.8)$ & 0.08 \\
\hline
\end{tabular}


Table 3 - Average variation in the percentage of CD4+ T lymphocytes and viral load in dual and triple therapy after 8 to 12 weeks of treatment, CTR-DIP, 1998 through 2001

\begin{tabular}{lccc}
\hline Variable & \multicolumn{2}{c}{ Treatment groups } & p \\
\cline { 2 - 3 } & $\begin{array}{c}\text { Dual }(\mathbf{n}=\mathbf{5 8}) \\
\text { Mean (SD) }\end{array}$ & $\begin{array}{c}\text { Triple }(\mathbf{n}=\mathbf{4 3}) \\
\text { Mean (SD) }\end{array}$ & \\
\hline CD4+ percentage & $+6.1(8.9)$ & $+4.0(12.4)$ & 0.38 \\
CD4+, $<1$ year $(n=13 ; 19)$ & $+609(796)$ & $+450(506)$ & 0.55 \\
CD4+, 1 to 5 years $(n=34 ; 19)$ & $+266(596)$ & $+352(472)$ & 0.64 \\
CD4+, > 5 years $(n=11 ; 5)$ & $-36(443)$ & $+205(143)$ & 0.27 \\
Viral load, copies $/ \mathrm{mL}$ & $-671.284(1.505 .680)$ & $-1.598 .123(3.102 .535)$ & 0.11 \\
Viral load, logarithm & $-1.2(1.3)$ & $-2.5(1.7)$ & 0.001 \\
\hline
\end{tabular}

CTR/DIP = Training and Referral Center for Infectious and Parasitic Diseases; SD = standard deviation.

Gortmaker et al. ${ }^{14}$ (PACTG 219) highlighted the benefits obtained after the introduction of PI in pediatrics, mainly the reduction in mortality rates among children infected with HIV/AIDS. Special attention should be given to the method used in the present study. The retrospective analysis of treatments is important to draw up new guidelines. Disease severity is an important variable to be controlled $7,8,14$ and we did that in this study. The difference between the therapeutic regimens was even greater in more severely ill patients.

By taking into consideration the predictive values for therapeutic response in children, described in the literature, ${ }^{29}$ the present study defined the baseline CD4+ count as a predictor of the first therapeutic failure (Table 2 ). These values correspond to immunologic category 2 , which defines the indication for treatment. The CD4+ count should take the pediatric age group into consideration, and this count might have been hindered by the small number of patients in each group.

The baseline viral load did not have a predictive value in the occurrence of therapeutic failure. This assessment might have been hindered by the difficulty in determining which values may be considered high for treatment initiation. 10,13,23,29

The aim of therapy is to provide a more remarkable reduction of the viral load for as long as possible. In addition, the detection of viral replication is related to the greater probability of resistance and virologic failure. $11,22,24$ With HAART, adults are able to suppress the viral load for at least 2 years, and this is more rare among children. Consequently, the reduction of the viral load meets the criteria established by the guidelines for therapeutic success. 23,24 In this study, efficient response had an average duration of 2 years and 10 months for patients on triple therapy, which is also the case in adults.

Given the currently available ARV drugs, triple therapy is recommended for HIV-infected children when treatment is indicated, due to a better virologic response and longer duration of the therapeutic regimen, as described in the literature and according to the results of this study. When indicated, it is essential that the most efficient ARV therapy available be used, since patients without previous exposure to these drugs have a better therapeutic response. 22,24,29

\section{References}

1. US Food and Drug Administration. Antiretroviral HIV drug approvals and pediatric labeling information [updated Oct 2005]. http://www.fda.gov/oashi/aids/status.html.

2. Englund JA, Baker CJ, Raskino C, McKinney RE, Petrie B, Fowler MG, et al.; For the AIDS Clinical Trials Group 152 Study Team. Zidovudine, didanosine or both as the initial treatment for symptomatic HIV-infected children. N Engl J Med. 1997;336: 1704-12.

3. McKinney RE Jr, Johnson GM, Stanley $\mathrm{K}$, Yong $\mathrm{FH}$, Keller A, $\mathrm{O}$ 'Donnell $\mathrm{KJ}$, et al. A randomized study of combined zidovudinelamivudine versus didanosine monotherapy in children with symptomatic therapy-naïve HIV-1 infection. The Pediatric AIDS Clinical Trials Group 300 Study Team. J Pediatr. 1998;133:500-8.

4. A randomized double-blind trial of the addition of lamivudine or matching placebo to current nucleoside analogue reverse transcriptase inhibitor therapy in HIV-infected children: the PENTA-4 trial. Paediatric European Network for Treatment of AIDS. AIDS. 1998;12:F151-60

5. Essajee SM, Kim M, Gonzales C, Rigaud M, Kaul A, Chandwani $S$, et al. Immunologic and virologic responses to HAART in severely immunocompromised HIV-1 infected children. AIDS. 1999; 13:2523-32.

6. Gibb DM. A randomized trial evaluating three NRTI regimens with and without nelfinavir in HIV-infected children: 48 week follow-up from the Penta 5 trial. AIDS. 2000;14 Suppl 4:58. 
7. Nachman SA, Stanley K, Yogev R, Pelton S, Wiznia A, Lee S, et al. Nucleoside analogs plus ritonavir in stable antiretroviral therapy-experienced HIV-infected children - a Randomized Controlled Trial. JAMA. 2000;283:492-8.

8. Gibb DM, Newberry A, Klein N, Rossi A, Grosch-Woener I, Babiker A. Immune repopulation after HAART in previously untreated HIV-1 infected children. Paediatric European Network for Treatment of AIDS (PENTA) Steering Committee. Lancet. 2000;355:1331-2.

9. Burchett SK, Carey V, Yong F, Sullivan J, Sulzbacher S, Civitello $\mathrm{L}$, et al. Virologic activity of didanosine (ddI), zidovudine (AZT) and nevirapine (NVP) combinations in pediatric subjects with advanced HIV disease (ACTG 245). In: 5th Conference on Retroviruses and Opportunistic Infections; 1998 Feb 1-5; Chicago. (Abstract 271.)

10. Luzuriaga K, McManus M, Catalina M, Mayack S, Sharkey M, Stevenon $M$, et al. Early therapy of vertical human immunodeficiency virus type 1 (HIV-1) infection: control of viral replication and absence of persistent HIV-1 specific immune responses. J Virol. 2000;74:6984-91.

11. Palumbo PE. Antiretroviral therapy of HIV infection in children. Pediatr Clin N Am. 2000;47:155-69.

12. Ho DD. Time to hit HIV, early and hard. N Engl J Med. 1995;333: 450-1.

13. Sharland M, Gibb D, Giaquinto C. Current evidence for the use of paediatric antiretroviral therapy - a PENTA analysis. Eur J Pediatr. 2000;159:649-56.

14. Gortmaker SL, Hughes M, Cervia J, Brady M, Johnson GM, Seage $\mathrm{GR}$, et al. Effect of combination therapy including protease inhibitors on mortality among children and adolescents infected with HIV-1. N Engl J Med. 2001;345:1522-8.

15. de Martino M, Tovo PA, Balducci M, Galli L, Gabiano C, Rezza G, et al. Reduction in mortality with availability of antiretroviral therapy for children with perinatal HIV-1 infection. Italian Register for HIV Infection in Children and the Italian National AIDS Registry. JAMA. 2000;284:190-7.

16. Dornadula $G$, Zhang $H$, VanUitert B, Stern J, Livornese L Jr, Ingerman MJ, et al. Residual HIV-1 RNA in blood plasma of patients taking suppressive highly active antiretroviral therapy. JAMA. 1999;282:1627-32.

17. Furtado MR, Callaway DS, Phair JP, Kunstman KJ, Stanton JL, Macken CA, et al. Persistence of HIV-1 transcription in peripheralblood mononuclear cells in patients receiving potent antiretroviral therapy. N Engl J Med. 1999;340:1614-22.

18. Condra $\mathrm{JH}$. Resisting resistance: maximizing the durability of antiretroviral therapy. Ann Intern Med. 1998;128:951-4.

19. Hirschel B, Francioli P. Progress and problems in the fight against AIDS. N Engl J Med. 1998;338:906-8.

20. Tebas $P$. When should antiretroviral therapy be initiated? Medscape HIV/AIDS. 2002;8. http://www.medscape.com/ Medscape/HIV/journal/2002/v08.n01/mha0117.02.teba/ mha0117.02.teba-01.html. Access: 01/02/2001.
21. Eron IE. Initial therapy: when to start, what to start with? In: 8th Conference on Retroviruses and Opportunistic Infections; 2001 Feb 4-8; Chicago. http://www.medscape.com/viewarticle/ 416522. Access: 28/12/2001.

22. Gallant JE. Antiretroviral therapy: starting, continuing and fixing. Medscape HIV/AIDS Annual Update 2001. http:// hiv.medscape.com/Medscape/HIV/AnnualUpdate/2001/ $\mathrm{m} \mathrm{ha}$. update06.03.gall/m ha04.gall-01.h tm I. Access: 22/11/2001.

23. Brasil, Ministério da Saúde, Coordenação Nacional DST/AIDS. Guia de tratamento clínico da infecção pelo HIV em crianças. Consenso sobre terapia anti-retroviral para crianças infectadas pelo HIV. Brasília: Ministério da Saúde; 2004. http:// www.aids.gov.br/data/documents/storedDocuments/ \%7BB8EF5DAF-23AE-4891-AD36-1903553A3174\%7D/ \% 7B88FCFB9A-6418-47C5-9D9F-70440233DE94\%7D/ consensocriancas2004.pdf. Acesso: 13/03/2005.

24. US Department of Health and Human Services, HIV/AIDS Treatment Information Service. Guidelines for the use of antiretroviral agents in pediatric HIV infection [updated on Nov 3, 2005]. http://aidsinfo.nih.gov/ContentFiles/Pediatric Guidelines.pdf. Access: 20/11/2005.

25. Centers for Disease Control and Prevention. Revised classification system of human immunodeficiency virus infection in children less than 13 years of age. MMWR. 1994;43:1-10.

26. Sharland M, di Zub GC, Ramos JT, Blanche S, Gibb DM, PENTA Steering Committee. PENTA guidelines for the use of antiretroviral therapy in paediatric HIV infection. Pediatric European Network for Treatment of AIDS. HIV Med. 2002;3:215-26.

27. Sterling TR, Chaisson RE, Moore RD. HIV-1 RNA, CD4 Tlymphocytes and clinical response to highly active antiretroviral therapy. AIDS. 2001;15:2251-7.

28. Mitsuyasu RT. How long can you go? Predictive value of pretreatment CD4+ cell count and viral load. In: 8th Conference on Retroviruses and Opportunistic Infections; $2001 \mathrm{Feb}$; Chicago. http://www.medscape.com/viewarticle/416528 Access: 28/12/ 2001.

29. Palumbo PE, Raskino C, Fiscus S, Pahwa S, Fowler MG, Spector SA, et al. Predictive value of quantitative plasma HIV RNA and CD4+ lymphocyte count in HIV-infected children. JAMA. $1998 ; 279: 756-61$.

Correspondence:

Jorge A. Pinto

Faculdade de Medicina - UFMG

Av. Alfredo Balena, 190, $3^{\circ}$ andar (DIP - Sala 3054), Santa Efigênia

CEP 30130-100 - Belo Horizonte, MG - Brazil

E-mail: jpinto@medicina.ufmg.br 